Teaching and Learning, Vol 4, No. 3, 2008

\title{
Exploring the relationship between physical education and physical activity
}

\author{
Chunlei Lu: Brock University, Canada \\ Amanda De Lisio: University of British Columbia, Canada
}

\begin{abstract}
The lack of knowledge within the educational profession, related to physical activity and physical education, is jeopardizing the implementation of quality physical education at both elementary and secondary school levels. Despite the effort of the academic community to broaden the awareness of each concept, an alarming number of people within the educational profession still reference each term interchangeably (AAHPERD, 2008; Fishburne \& Hickson, 2005). The purpose of the following paper is to re-examine the relationship between physical activity and physical education in an attempt to further progress the understanding of, and identify the appropriate function of, each within a teaching-learning environment. The paper will build on current literature involving the correlation between physical activity and physical education. Ultimately, by further clarifying the role of each, the paper can support every educator in the successful implementation of Daily Physical Activity (DPA) and a quality physical education program for every public school.
\end{abstract}

\section{Introduction}

Within the educational profession, many people do not recognize the difference between physical education and physical activity (AAHPERD, 2008). The increasing popularity of school-based health policies, intended to combat childhood obesity, will demand the clarification of each term. Appreciating the difference between physical education and physical activity will allow people to optimize the potential of each in the development of healthy, active children. However, in ignoring the misconception, we breed a harmful practice in the deliverance of a quality physical education curriculum (Fishburne \& Hickson, 2005). This paper is intended to act as an extension to previous literature relating each concept to further clarify and strengthen physical education and physical activity in theory and practice.

\section{Similarities between physical education and physical activity}

The similarities between physical education and physical activity largely contribute to the tendency of people to use each term interchangeably. After all, it would be easier to relate the two rather than separate physical education and physical activity based on any difference. Both usually involve movement and stress the physical aspect of the human body. When observing a physical education class, one is likely to observe a student engaging in some form of physical activity. Yet, further investigation would likely cause an individual to realize that physical activities are conducted beyond the classroom such as at home or within the public. Thus, a quality physical education program should encompass more than merely a collection of physical activities. 


\section{What is physical education?}

Physical education is not simply any activity or sport intended to increase heart rate or lead to the expenditure of energy. It is an academic subject, which utilizes physical activities as a vehicle to achieve an educational outcome (or objective, expectation) as prescribed by the curriculum. As an integral component of the total education of a child, physical education will persist to contribute to the growth and development of all children primarily through a positive movement experience (Pangrazi $\&$ Gibbons, 2008). Quality physical education will offer the best opportunity to expose all children to a variety of well-planned physical activities intended to teach the necessary movement literacy needed to foster and sustain a lifetime of active and healthy living. Within physical education, each learning domain (i.e., psychomotor, cognitive, and affective) can be successfully addressed. As phrased nearly a century ago by Clark Hetherington (1910), education through the physical (in stead of education of the physical) was one mentality, which emphasized an innovated physical education curriculum capable of addressing each learning domain. Currently, no other school program is designated to help children develop their movement literacy and ultimately, build the basis for an active healthy lifestyle. Resultantly, society cannot afford to ignore the importance of a quality physical education program particularly, during the current obesity epidemic.

\section{What is physical activity?}

By contrast, physical activity refers to any bodily movement produced by skeletal muscles that result in an expenditure of energy (Pangrazi \& Gibbons, 2008). An organizational game or sport will also be considered as a type of physical activity that is usually planned, structured, governed by an official or rule-based, and often engaged in competitively. Physical activities are presented in an array of opportunities throughout any given day and are often difficult to avoid - despite the great effort, one may devote to do so. The Public Health Agency of Canada (2008) identified several daily duties as a form of physical activity, such activities included, housecleaning, yard and garden work, grocery shopping, and walking a dog. Although a physical component will strongly dictate the performance of each activity, as emanated within a physical education class, education or learning will not be the primary intention of any physical activity. Therefore, every physical educator, regardless of their generalist or specialist status, are responsible for providing some form of education while teaching physical education in a public school. In contrast to the educational system, yet within the realm of athletic development, a coach, athlete, and fitness instructor are likely not qualified to teach physical education regardless of the sport-specific training obtained. Only an individual trained in the teacher education program and certified by a governing body (e.g., the provincial ministry of education) will possess ample pedagogical and curricular knowledge to orchestrate a quality physical education program.

\section{Is physical education an academic subject?}

As indicated above, physical education is an academic subject, which is devoted to the development of movement literacy. Children are not born movement literate nor does the literacy develop naturally through growth and maturation. As part of developing a whole child, movement literacy will entail not only learning about movement but also 
learning through movement, and is evocative of both body and mind (Kentel \& Dobson, 2007). The embodied learning experienced in physical education will develop motor competence through each movement concept (i.e., body awareness, space awareness, effort, and relationship) and fundamental movement skill (i.e., locomotion, manipulation, and stability). Furtherance to the development of motor competencies will also lend to a diverse physical activity repertoire, which will increase appreciation of health-related fitness and optimize the enjoyment experienced in a physical activity setting. The outcome of movement literacy development is reflected within the criteria outlined by CAHPERD (2005) as people who (a) acquire skills to enable them to perform a variety of physical activities, (b) acquire skills that will help them to become physically fit, (c) participate regularly in physical activity because it is enjoyable and exhilarating, (d) understand and value physical activity, (e) understand that physical activity can support self-expression and provide for social interaction with others, (f) display responsible and social behaviour during physical activity, and ( $\mathrm{g}$ ) display an understanding of and a respect for all people during physical activity. Similar to the need for children to become literate in numeracy or language, children need to develop movement literacy. This literacy will act as a language to physical movement and is dependent on the accessibility of a quality physical education program.

Movement literacy development can also work in association with the development of other types of literacy (e.g., scientific literacy, mathematical literacy, health literacy). A physical education class is an excellent platform for any teacher to construct an interdisciplinary approach to learning. For example, a student can collaborate with a group to create a vocabulary term with their bodies or explore a cultural dance to add to a discussion involving cultural identity. Numeracy and science can be incorporated into the development of a personal fitness plan. Physical education can promote literacy across the curriculum and elicit an alternative approach to educating children as opposed to the traditional method of teaching each subject in isolation.

\section{To plan physical activities or physical education}

In Canada and throughout Western countries, the goal of physical education is to primarily assist students to develop necessary knowledge, skills, and attitudes (KSAs) that lead toward an active healthy lifestyle (Turkington, 2001). In creating any instructional plan, an educator would not primarily consider every desired instructional activity. Before any specific activity can be planned, an overall goal for the unit or course of study must be determined. Once a goal for a unit is established, a teacher may then progress backward to the organization of each individual learning task. The same can be regarded for planning a quality physical education program. Rather than selecting several physical activities and planning a unit involving each, a physical educator must primarily consider the overall goal of the program. With the end in mind, a teacher is less likely to become lost in every detail, which may attempt to bombard instruction (i.e., students' interest, teacher expertise, school tradition, resource availability, time, and district/school policies).

In identifying an instructional goal, an educator may uncover a particular activity, which would prove to be extremely beneficial for their class to experience despite being beyond the movement repertoire of the teacher. In such a case, a physical educator may consult an expert from the community or invite her/him to the class to assist in their understanding. In pushing the movement envelope of a physical educator, a class 
particularly a less-skilled student, will inevitably feel more comfortable in the learning environment.

Within the education realm, assessment is a popular term. In creating a physical education program, which is designed, to only assess traditional physical activities (e.g., basketball, volleyball, badminton), a teacher may never stimulate the most athletic student and will persist to segregate the less-skilled populace of the class. The impact will likely cause people whom are less physically proficient to reject physical education and possibly, any form of physical activity. Contrarily, the skilled population will likely either take pleasure in physical education or become bored with the lack of a motor stimulant. By design, the class will cultivate only the superficial goal of physical education, which is to produce more athletically inclined people. In favouring this traditional physical education mentality, an educator will cease to cater to the enjoyment of physical activities by reinstating the athletic stereotype. The underlying goal then of physical education must not be to only develop athletic talent but rather, to instill in every child, the love for regular participation in physical activity and healthy active living. Evidently, the educational system must differ from the economic wealth of a nation in that the economy may fuel the rich get richer approach but public education cannot every child will progress forward regardless of their individual abilities.

\section{Physical activities are intended to serve physical education}

A physical educator must seek to provide activities, which a child can learn from. Any type of physical activity, including sports, can be included in a physical education program. Yet, every activity must be carefully selected and tailored to the need and uniqueness of a class.

When selecting an educational activity for physical education, five categories should be considered: educational dance, educational games, educational gymnastics, educational individual activities, and educational alternative environment activities. As indicated earlier, learning must be pursued. A comparative table outlining the difference between educational gymnastics and competitive gymnastics is provided in Table 1. Particular attention should be granted to those activities which are easily accessible within a community, emphasize personal fitness and foster lifelong participation. A single activity is incapable of reaching every child and curricular outcomes or expectations. Therefore, it would be impractical for an educator to select one activity to prescribe for an entire program. Teaching from each category will ensure program diversity while increasing the likelihood an educator will appeal to each child and accomplish every outcome or expectation.

A traditional sport can be easily modified in order to accommodate to a particular level and need of a child or entire class. For example, primary children struggle with the height of a basketball rim and volleyball net, the weight and size of a soccer ball, and the tempo and pace of a dance, which can all be modified in order to increase the level of success experienced by an entire class. A physical activity can be modified or adjusted in relation to the number of people, equipment, space, or structure of play (Siedentop \& Tannehill, 2000). In so doing, a class may take ownership over a particular physical activity because it will reflect the ability of the class. If an educator failed to modify a given game, the activity will likely not be developmentally appropriate and will negate from the overall function of every physical activity - to serve in the fulfillment of each outcome or expectation intended for a particular physical education lesson. 
Table 1. Differences between educational and competitive gymnastics:

\begin{tabular}{|l|l|l|}
\hline & Educational & Competitive \\
\hline Goal & educational & winning \\
\hline Learning drive & for self & for audience \\
\hline Nature & non-competitive & competitive \\
\hline Form & unlimited & limited \\
\hline Prerequisite & not required & athletic training \\
\hline Intensity & mild or moderate & strenuous \\
\hline Facility/equipment & various; open-ended & high quality and specific \\
\hline Safety & extremely important & encourage risk-taking \\
\hline Assessment & flexible & Strict \\
\hline
\end{tabular}

\section{The relationship between physical education and daily physical activity (DPA)}

Daily physical activity (DPA) is an initiative mandated by the provincial government in Alberta and Ontario in an attempt to make every school across the province a healthier learning environment. "The goal of DPA in Ontario is to enable all elementary students to improve or maintain their physical fitness and their overall health and wellness, and to enhance their learning opportunities" (Ministry of Education, 2005, p. 1). The initiation of such a mandate is in response to the current health crisis associated with physical inactivity within society. DPA is based on the belief that healthy children are better able to learn and that a school community is able to provide the supportive environment for a student to acquire the necessary information to lead a healthy, active lifestyle. It has been implemented in schools in Alberta (requiring a minimum of 30minutes of DPA in G1-9) and in Ontario (requiring a minimum of 20-minutes of DPA in G1-8) since the fall of 2005 (Alberta Education, 2008; Ministry of Education, 2008).

DPA should be considered as a new component of the physical education program within every elementary school in Alberta and Ontario. However, DPA must not replace physical education and the fact that it does will continue to reinforce the confusion surrounding physical activity and physical education. DPA is not meant to foster learning - it is to act as an opportunity for children to become active within the school. The current nature of DPA, will allow it to be facilitated by any certified educator, and/or an individual that does not have a teaching certificate (i.e., a fitness instructor, coach, public health agent or member of the community) whereas, physical education must be taught by a certified professional.

Although the physical education class can be a place to implement DPA, it should NOT be a physical activity or physical training class. Time engaged in physical activity should be maximized in physical education; however, the organization of time can be distributed amongst each category - instructional time, managerial time, physical activity time, and wait-time. Instructional time is classified as the time used to explain and demonstrate a desired task such as a skill or game. Managerial time is any time used to 
organize the class and allocate equipment. During physical activity time, children are physically engaged and moving throughout the designated space. Finally, wait-time is any additional time within a lesson in which the children are not occupied by instructional, managerial, or physical activity time. Each type of time discussed above, except for wait-time, is necessary to the structure of a lesson. Unfortunately, research has shown that wait-time generally occupies as much as $25 \%$ of a physical education class, instructional time is between $15-30 \%$, managerial time is anywhere from 20 to $25 \%$ and physical activity time ranges from 20 to $40 \%$ of class time (Siedentop \& Tannehill, 2000).

Ideally, instructional and managerial time should be optimized, wait-time minimized, and physical activity time maximized. Therefore, a qualified and knowledgeable physical educator is crucial to the deliverance of a quality physical education lesson. Yet, it is important to note, physical activity time should not be regarded more important than instructional time. Carefully planned content is delivered during instructional time while managerial time and physical activity time are used to generate learning. However, there has been an emphasis on physical activity time for the benefit of health (not only for learning) in physical education. For example, an increase to physical activity time has been proposed from approximately 36 to $50 \%$ by 2020 in the physical education class in the United States. This proposal is in favour of the current drive toward a more physically active and fit classroom (McKenzie, 2007).

In relation to DPA, only time spent engaged in physical activity should be accounted. If required, an educator may decide to use regular class time to explain an activity employed during DPA. The goal of DPA is to increase the activity level of an entire class. This goal cannot effectively be achieved if children are inactively retaining instruction during the time designated for physical activity. Physical education will likely provide the most appropriate outlet for an educator to address an activity, which will later be used for DPA. Consequently, the instruction granted during physical education and daily physical activity will differ significantly and parallel the difference in instruction offered during recess and class time. Time in a physical education should be structured to a particular educational outcome, which will reveal itself through instruction. Contrarily, DPA may be successfully implemented without any instruction from an educator or fitness professional. The initiative was meant to supplement curricular content and enhance the educational experience of every child; however, it is not meant to replace physical education (or any other subject). Bear in mind, DPA will aim to offset the growing rate of childhood obesity. Physical education will also combat the current health epidemic; however, a quality program will also address the future health of a population by teaching children and youth the information needed to lead the healthiest life possible. The fact that DPA may replace, or question the integrity of physical education, is a reflection of the value placed on healthy living within society and likely, the contributing factor to the increasing occurrence of death and illness related to physical inactivity.

\section{Conclusion}

Understanding of the difference between physical education and physical activity is vital to the success of the physical education program throughout Canada and across the globe. In addition, accepting this difference will also lend to the success of daily physical activity within Ontario and Alberta. As an academic subject, physical education must utilize physical activities as a vehicle to drive teaching and learning to the 
development of movement literacy. Resultantly, every physical activity chosen by an educator must be tailored to serve the goal of their specific program. Although, learning is not necessarily a direct outcome of physical activity, it must be an outcome of physical education. Physical activities should never represent the goal of any lesson but rather the method used to help achieve the goal of physical education. 


\section{References}

AAHPERD (American Alliance for Health, Physical Education, Recreation \& Dance) (2008). Is it physical education or physical activity? Retrieved March 8, 2008 from http://www.aahperd.org/naspe/template.cfm?template=difference.html

Alberta Education (2008). Daily physical activity initiative. Retrieved March 8, 2008 from http://education.alberta.ca/teachers/resources/dpa.aspx

CAHPERD (Canadian Association for Health, Physical Education, Recreation, \& Dance) (2005). What is a physically educated person? Retrieved March 8, 2008 from http://www.cahperd.ca/eng/physicaleducation/story_detail.cfm?id=68

Fishburne, G. J., \& Hickson, C. (2005). What is the relationship between physical education and physical activity? Retrieved March 8, 2008 from http://www.cahperd.ca/eng/advocacy/issue_summary.cfm?id=6

Hetherington, Clark (1910). Fundamentals education. American Physical Education Review, 15, 629-635.

Kentel, J. A., \& Dobson, T. M. (2007). Beyond myopic visions of education: Revisiting movement literacy. Physical Education and Sport Pedagogy, 12(2), 145-162.

Mandigo, J. (2005). Presenting the evidence: Quality physical education for Canadian children and youth. Retrieved February 28, 2008 from http://www.cahperd.ca/ eng/advocacy/tools/documents/PresentingTheEvidence.pdf

McKenzie, T. (2007). A public health perspective: For PETE's sake. Paper presented at the 2007 History and Future Directions of Research on Teaching and Teacher Education in Physical Education Conference, Pittsburgh, PA.

Ministry of Education. (2005). Policy/Program Memorandum No. 138: Daily Physical Activity in Elementary Schools. Retrieved January 18, 2008, from http://www.edu.gov.on.ca/extra/eng/ppm/138.html

Ministry of Education. (2008). Daily physical activity. Retrieved May 8, 2008 from http://www.edu.gov.on.ca/eng/teachers/dpa.html

Pangrazi, R. P., \& Gibbons, S. L. (2008. Dynamic physical education for elementary school children $\left(2^{\text {nd }}\right.$ Canadian ed.). Toronto, Ontario: Pearson Education Canada.

Public Health Agency of Canada (2008). Physical activity guides. Retrieved March 8, 2008 from http://www.phac-aspc.gc.ca/pau-uap/fitness/downloads.html

Siedentop, D., \& Tannehill, D. (2000). Developing teaching skills in physical education ( $4^{\text {th }}$ eds.). Mountain View, CA: Mayfield Publishing Company.

Turkington, H. D. (2001). Physical education in Canada. FIEP Bulletin, 71 (1-2), $42-46$. 